\title{
HUMAN SYSTEMS INTEGRATION IN THE FEDERAL GOVERNMENT
}

\author{
Patricia M. Jones, and Gaye L. Graves, NASA Ames Research Center, (Co-chairs), Terry Allard, Office of \\ Naval Research, Jack Blackhurst, Air Force Research Laboratory, David J. Fitts, NASA Johnson Space \\ Center, Sean Peters, Nuclear Regulatory Commission, Dino Piccione, Federal Aviation Administration, \\ Lawrence G. Shattuck, Naval Postgraduate School
}

\begin{abstract}
Human Systems Integration principles and methods can be used to help integrate people, technology, and organizations in an effective and efficient manner. Over the past decade, a wide range of tools, techniques, and technologies have been developed by federal agencies to achieve significant cost and performance benefits. In this discussion, we will explore trends in military human systems integration and learn about the critical role being played by human performance and effectiveness research. We will also examine case studies on the planning and design of future human space flight vehicles, the national air space system and the first nuclear reactors to be built in the United States in over 30 years. And with an eye toward sustaining the discipline's principles and methods, we'll take a look at educating and training the next generation of human systems integration practitioners.
\end{abstract}

\section{TRENDS IN NAVY AND MARINE CORPS HUMAN SYSTEMS INTEGRATION Terry Allard}

The skyrocketing costs of people coupled with the increases in areas such as network-centric warfare, unmanned and robotic systems, irregular warfare, and automated medical care are driving the evolving definitions of human-systems integration in Navy and Marine Corps systems. Access to every-growing data networks increasingly overloads human operators and decision makers; new decision support systems must be developed that can search for decision-critical data and transform it into useful information. Increasing dependence on unmanned vehicles provides new challenges for human supervisory control. Pushing more autonomy to artificially intelligent agents will create new obstacles for monitoring and directing multi-agent systems and maintaining human situation awareness in complex, dynamic military operations.

Multi-agent teams of human, software and mobile elements will be required at all system levels, and require new command and control concepts. Increasing costs of people will require more efficient and effective use of people, reduced training time and reduced training requirements through better human-centered design. Advances in social and cultural sciences are needed to understand the new threats of asymmetric warfare. Advances in closed-loop control inpatient monitoring systems will improve battlefield medical care and save lives by extending the "golden hour" after injury and stabilizing patients as casualties are evacuated from the point of injury.

\section{U.S. AIR FORCE HUMAN PERFORMANCE OPTIMAZATION AND SUSTAINMENT THROUGH HUMAN SYSTEMS INTEGRATION Jack Blackhurst}

The Air Force Research Laboratory's Human Effectiveness Directorate is composed of a diverse group of scientists and engineers who study developing technologies specific to the human element of warfighting capability. They are leading the Air Force in its human-centered research, and they integrate biological and cognitive technologies to optimize and protect the airman's capabilities in flight, combat, space, and cyberspace.

Working together with the Human Performance Integration Directorate, the focus areas include human performance optimization and human performance sustainment through Human Systems Integration (HSI). HSI is mandated by Air Force policy. The directorates provide a bridge among the acquisition communities and are a lead integration agent for the promotion, guidance, consultation, and implementation of HSI. HSI consulting services and technical advisory support are provided to capability requirements developers, project managers, engineers, and other Air Force activities.

\section{LESSONS LEARNED FROM HUMAN SYSTEMS INTEGRATION IN NASA's CONSTELLATION PROGRAM David J. Fitts}

With each new NASA human spaceflight program, human factors engineering (HFE) and human systems integration (HSI) have been more deeply interlaced into program practices. In NASA's most recent human spaceflight program--the Constellation Program (CxP)--NASA successfully established HFE/HSI teams at the Program level and in $\mathrm{CxP}$ projects for the Crew Exploration Vehicle, nextgeneration Extravehicular Activity (EVA) suits, and a lunar lander. High quality HSI requirements were vetted into $\mathrm{CxP}$ processes and the HFE/HSI teams were provided equal program/project status to other managers in systems engineering and integration organization structures.

Areas of endeavor previously not formally assigned to HFE practioners became part of the discipline's lead responsibilities--e.g. net habitable volume and handling 
qualities--and other areas of endeavor--e.g., anthropometry and biomechanics--grew stronger in $\mathrm{CxP}$ practice with more rigorous validation and verification techniques than those used in previous human spaceflight projects. This presentation provides an overview and lessons learned for HFE/HSI engagement in the next human spaceflight program.

\section{HUMAN FACTORS AIR TRAFFIC CONTROL RESEARCH AND DEVELOPMENT: MODERNIZING THE NATIONAL AIRSPACE SYSTEM Dino Piccione}

The Federal Aviation Administration (FAA) is planning an extensive modernization of the National Airspace System (NAS). This modernization involves the phased introduction of automation and new technology to increase capacity and efficiency for a service that has historically been a manual process. The planned changes have profound implications for the design of automated systems as well as the new workforce.

There are numerous Human Factors challenges to be met in terms of setting requirements for system design, making decisions on how human performance will be affected, performing proactive human error hazard analyses, defining new roles and responsibilities of the actors in the NAS, generating new personnel selection criteria and new requirements for training. To meet these challenges the FAA is implementing a Human System Integration approach to manage change in the NAS.

The human factors function in the FAA has been drafted as part of the system engineering team to play a role in defining the architecture for the future NAS. For the first time, the human actors in the NAS are part of the architectural plan for the future. The Human System Integration Roadmap is part of the FAA Enterprise Architecture. This roadmap is evolving as a reflection of the major human factors efforts and decisions to meet the challenges of NAS modernization.

\section{HUMAN FACTORS CONSIDERATIONS FOR NEW AND ADVANCED NUCLEAR POWER PLANT CONTROL ROOM DESIGN Sean Peters}

Plans to begin constructing nuclear power plants (NPPs) within the next several years indicate the renewed interest in nuclear energy. The new generation of plants will differ from the existing fleet in several important ways, including the design of the reactors, the instrumentation and control (I\&C), and the human-system interface (HSI).

First, in terms of the reactor design, the "near term" next generation plants are mostly light water reactors that rely on passive, rather than active safety features, or for later deployment, they comprise non-light water designs that may include concurrent control of multiple modules from a common control room.
Second, the next generation plants will be designed using digital I\&C (DI\&C) technology, opposed to the predominantly analog I\&C technology used in the current fleet of plants. DI\&C systems provide the capability to implement control algorithms that are more advanced than have been used in plants to date, including nonlinear control methods, fuzzy logic, neural networks, and adaptive control. Moreover, these systems will provide the capability for increased automation that make greater use of interactions between personnel and automatic functions, leading to more intricate control of plant systems and greater complexity.

The third key difference between the current and new and advanced plant designs is their human-system interface (HSI). Rather than using analog controls and displays, the next generation plants are being designed with computer-based HSIs organized into sit-down workstations. Operators will be monitoring the plant through screen-based displays selected from networks of hundreds or even thousands of display pages. Control of plant equipment will be accomplished through soft controls that can be accessed through computer workstations, and computer-based procedures will be employed that allow control actions directly from the procedure display, or they may be automated with the operator authorizing the procedure's embedded control functions to take actions.

Taken together, these advances in technology will lead to concepts of operation that are different from those found in currently operating NPPs. The potential benefits of the new NPP technologies should result in more efficient operations and maintenance. However, if the technologies are poorly designed and implemented (i.e., integrated), there is a potential to reduce human reliability, increase errors, and negatively impact human performance, which could result in a detrimental effect on safety. To address these concerns, the $\mathrm{NRC}$ has developed a roadmap to identify human performance research that may be needed to support the review of licensees' implementation of new and emerging technology in the next generation of NPPs.

\section{INNOVATIONS IN HUMAN SYSTEMS INTEGRATION TRAINING AND EDUCATION OF FUTURE PRACTITIONERS Lawrence G. Shattuck}

One mark of a healthy discipline or profession is the dynamic interplay between practitioners and the training and educational institutions that prepare the practitioners. An example of this interplay is when students and faculty engage in innovative research that pushes the boundaries of a discipline and practitioners can use the results of the research. Similarly, the innovations of the practitioners are passed back to the training and educational institutions where they are incorporated into the coursework.

The discipline of Human Systems Integration (HSI) is relatively new but this interplay between practitioner and 
training and educational institution is beginning to emerge at the Naval Postgraduate School (NPS). NPS offers both a four-course graduate level certificate in HSI and a resident Master of Science degree in HSI. Both programs are grounded in the DoD acquisition process and focus on those activities that will ensure the human operators, maintainers, supporters, and trainers are properly considered throughout the entire life cycle of a system.

Recent student and faculty research have led to important innovations in the curriculum that is influencing the way HSI is practiced. In addition, continuous communication between NPS and HSI practitioners throughout the Federal government ensures that the latest HSI tools, techniques, approaches, and processes are taught to the students. More work must be done in HSI training and education (as well as many other areas of HSI) before the discipline is mature. We are, however, moving in the right direction!

\section{SUMMARY}

Trends in advancing military technology, from more autonomy to artificially intelligent agents, will create new obstacles for monitoring and directing multi-agent systems and maintaining human situation awareness in complex, dynamic military operations. Coupled with the skyrocketing costs associated with the people who use the technology, the Office of Naval Research (ONR) addresses challenges to identify more efficient and effective use of people, reduce training time and training requirements through better humancentered design and human systems integration.

The Air Force Research Laboratory's (AFRL) Human Effectiveness Directorate is leading the Air Force in its human-centered research, as it integrates biological and cognitive technologies to optimize and protect the airman's capabilities in flight, combat, space, and cyberspace. Utilizing human-centered research, along with human systems integration methods and practices, it provides a bridge among the acquisition communities and is a lead integration agent for the promotion, guidance, consultation, and implementation of HSI within the Air Force.

In the National Aeronautics and Space Administration's (NASA) most recent human spaceflight program--the Constellation Program (CxP)--NASA successfully established HFE/HSI teams at the Program level and in CxP projects for the Crew Exploration Vehicle, next-generation EVA suits, and a lunar lander. This presentation provides an overview and lessons learned for HFE/HSI engagement in the next human spaceflight program.

The Federal Aviation Administration (FAA) is planning an extensive modernization of the National Airspace System (NAS). This modernization involves the phased introduction of automation and new technology to increase capacity and efficiency for a service that has historically been a manual process. To meet these challenges the FAA is implementing a
Human System Integration approach to manage change in the NAS.

Due to the renewed interest in nuclear energy, the Nuclear Regulator Commission (NRC) plans to begin constructing new nuclear power plants within the next several years. The plants will differ from the existing fleet in several important ways, including the design of the reactors, the instrumentation and control (I\&C), and the human-system interface (HSI). To address these issues, the NRC has developed a roadmap to identify human performance research that may be needed to support the review of licensees' implementation of new and emerging technology in the next generation of nuclear power plants.

One mark of a healthy discipline or profession is the dynamic interplay between practitioners and the training and educational institutions that prepare the practitioners. At the Naval Postgraduate School, continuous communication with HSI practitioners throughout the Federal government ensures that the latest HSI tools, techniques, approaches, and processes are taught to the students. Recent student and faculty research have led to important innovations in the curriculum that is influencing the way HSI is practiced. 